\title{
Biologi dan statistik demografi kutudaun Rhopalosiphum rufiabdominale (Sasaki) dan Tetraneura nigriabdominalis (Sasaki) (Hemiptera: Aphididae) di akar padi
}

\author{
Biology and demography statistic aphids Rhopalosiphum \\ rufiabdominale (Sasaki) and Tetraneura nigriabdominalis \\ (Sasaki) (Hemiptera: Aphididae) in rice roots
}

\author{
Purnama Hidayat $^{{ }^{*}}$, Harleni ${ }^{2}$, Yani Maharani ${ }^{3}$, Hermanu Triwidodo ${ }^{1}$ \\ ${ }^{1}$ Departemen Proteksi Tanaman, Fakultas Pertanian, Institut Pertanian Bogor \\ Jalan Kamper, Kampus IPB Dramaga, Bogor 16680
}

${ }^{2}$ Program Studi Entomologi, Sekolah Pascasarjana, Fakultas Pertanian, Institut Pertanian Bogor Jalan Kamper, Kampus IPB Dramaga, Bogor 16680

${ }^{3}$ Departemen Hama dan Penyakit Tumbuhan, Fakultas Pertanian, Universitas Padjadjaran Jalan Raya Bandung-Sumedang Km 21, Jatinangor 45363

(diterima November 2018, disetujui November 2019)

\begin{abstract}
ABSTRAK
Rhopalosiphum rufiabdominale (Sasaki) dan Tetraneura nigriabdominalis (Sasaki) merupakan spesies kutudaun yang ditemukan hidup di akar tanaman padi. Informasi tentang kisaran inang dan biologi $R$. rufiabdominale relatif lebih banyak diketahui dibandingkan dengan T. nigriabdominalis. Penelitian ini bertujuan mengetahui biologi dan statistik demografi kutudaun $R$. rufiabdominale dan T. nigriabdominalis yang hidup di akar tanaman padi. Kutudaun yang diperoleh dari akar padi sawah di Leuwiliang, Kabupaten Bogor dipelihara dan diperbanyak pada akar padi varietas Ciherang di laboratorium. Setiap nimfa instar satu kutudaun kohort yang sama diinfestasikan ke akar padi di dalam 60 wadah plastik untuk pengamatan biologi dan peubah statistik demografi. Peluang hidup $\left(1_{x}\right)$, keperidian harian $\left(m_{x}\right)$, dan rata-rata jumlah nimfa kutudaun yang dilahirkan oleh imago setiap harinya pada umur (x) digunakan untuk menghitung parameter statistik demografi. Hasil penelitian menunjukkan bahwa kedua spesies kutudaun tersebut masing-masing memiliki 4 stadia nimfa. Siklus hidup dan lama hidup $R$. rufiabdominale ialah 4,98 hari dan 15,94 hari dengan keperidian 67,44, sedangkan siklus hidup dan lama hidup T. nigriabdominalis ialah 5,25 hari dan 18,11 hari dengan keperidian 11,11. Kutu daun $R$. rufiabdominale memiliki tingkat pertumbuhan intrinsik (r) 0,46 hari dan waktu berlipat ganda (DT) 1,50 hari, sedangkan T. nigriabdominalis memiliki tingkat pertumbuhan intrinsik 0,14 hari dan waktu berlipat ganda 4,99 hari. Hasil penelitian ini menunjukkan bahwa meskipun lama siklus hidup kedua spesies kutudaun hampir sama, namun populasi $R$. rufiabdominale berkembang 3,5 kali lebih cepat dibandingkan dengan T. nigriabdominalis dan oleh karena itu berpotensi menjadi hama penting pada tanaman padi.
\end{abstract}

Kata kunci: keperidian, lama hidup, populasi, siklus hidup

\section{ABSTRACT}

Rhopalosiphum rufiabdominale (Sasaki) and Tetraneura nigriabdominalis (Sasaki) are aphid species found in the roots of rice plants. Information about the host range and biology of $R$. rufiabdominale is relatively known than $T$. nigriabdominalis. This study aims to determine the biology 
and demographic statistics of $R$. rufiabdominale and T. nigriabdominalis in the roots of rice plants. The aphids obtained from lowland rice roots in Leuwiliang, Bogor Regency were maintained and reared in Ciherang variety rice roots in the laboratory. Each individual of the 1st instar aphid nymph in the same cohort was infested into the roots of rice in 60 plastic containers for biological observations and statistical demographic variable data collection. Survivorship $\left(1_{\mathrm{x}}\right)$, fecundity $\left(\mathrm{m}_{\mathrm{x}}\right)$, and the average number of nymphs born by adult every day at age $(\mathrm{x})$ are used to calculate demographic statistical parameters. The results showed that the two species of the aphids have 4 nymph instars. Life cycle and longevity of $R$. rufiabdominale were 4.98 days and 15.94 days with fecundity of 67.44 respectively, whereas the life cycle and longevity of T. nigriabdominalis were 5.25 days and 18.11 days with fecundity of 11.11 respectively. $R$. rufiabdominale aphids have an intrinsic growth rate (r) of 0.46 days and a doubling time (DT) of 1.50 days, whereas T. nigriabdominalis has an intrinsic growth rate of 0.14 days and a doubling time of 4.99 days. The results of this study indicate that although the life cycle lengths of the two species are almost the same, the population of $R$. rufiabdominale develops 3.5 times faster than T. nigriabdominalis and therefore R. rufiabdominale has the potential to become an more important pest in rice plants.

Key words: fecundity, life cycle, longevity, population

\section{PENDAHULUAN}

Kutudaun umumnya hidup di bagian tanaman yang berada di atas permukaan tanah, seperti daun, bunga, buah, pucuk, dan ranting. Namun, ada beberapa spesies kutudaun yang hidup di akar tanaman yang letaknya berada di dalam tanah. Kutudaun yang hidup di akar tanaman itu dapat merugikan tanaman karena perannya sebagai hama. Kindler et al. (2004) melaporkan bahwa kutudaun spesies Rhopalosiphum rufiabdominale (Sasaki) dan Tetraneura nigriabdominalis (Sasaki) merupakan kutudaun yang menyerang akar tanaman padi di Oklahoma. Kedua spesies kutudaun tersebut juga dilaporkan menyerang akar tanaman padi di Laos (Saito et al. 2006).

Kutudaun ini memperoleh nutrisi dengan cara mengisap bagian dari akar padi. Populasi yang tinggi pada akar padi dapat menyebabkan gangguan fisiologis pada tanaman sehingga tanaman akan tumbuh kering dan kerdil, bahkan dapat menyebabkan tanaman menjadi mati. Kerusakan pada tanaman sangat dipengaruhi oleh pertumbuhan populasi hama. Menurut Price (1997), statistik demografi merupakan salah satu langkah awal dalam memelajari pertumbuhan populasi serangga. Demografi adalah analisis kuantitatif karakteristik suatu populasi, terutama hubungannya dengan pola pertumbuhan populasi, hubungan ketahanan, dan pergerakan populasi. Aspek demografi tersebut dapat dipelajari dalam bentuk neraca kehidupan. Neraca kehidupan akan menyajikan informasi mengenai peluang hidup, kelahiran, perkembangan, keperidian, dan kematian setiap individu dalam populasi.

Informasi mengenai biologi dan statistik demografi kutudaun di akar padi di Indonesia belum banyak dilaporkan sehingga informasinya masih sangat terbatas. Informasi tersebut merupakan informasi dasar dan informasi penting untuk menentukan strategi pengendaliannya. Berdasarkan uraian tersebut maka penelitian ini bertujuan untuk mengetahui biologi dan statistik demografi kutudaun $R$. rufiabdominale dan $T$. nigriabdominalis di akar padi.

\section{BAHAN DAN METODE}

\section{Lokasi dan waktu penelitian}

Penelitian dilakukan di Laboratorium Biosistematika Serangga, Departemen Proteksi Tanaman, Fakultas Pertanian, Institut Pertanian Bogor. Kegiatan penelitian dilaksanakan dari Juni 2014 sampai Juli 2015.

\section{Pengambilan sampel dan identifikasi kutudaun}

Kutudaun diperoleh dari akar padi sawah di daerah Leuwiliang, Kabupaten Bogor (Gambar 1). Tanaman padi yang terdapat kutudaun diambil dengan cara memotong tanaman tersebut dan dimasukkan ke dalam kotak pemeliharaan untuk perbanyakan. Sebelum digunakan untuk perbanyakan, kutudaun yang diperoleh terlebih dahulu diidentifikasi secara morfologi dengan acuan Blackman \& Eastop (2006). Identifikasi 


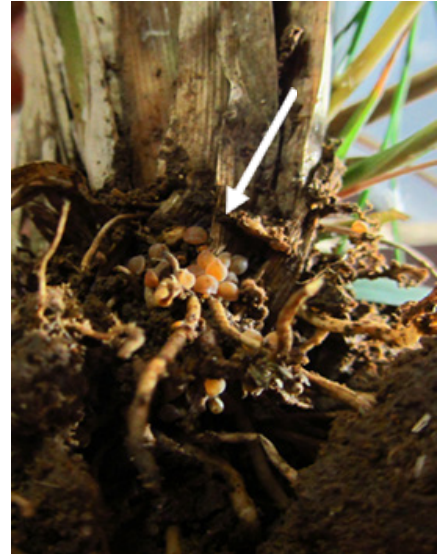

Gambar 1. Koloni kutudaun pada akar padi yang diperoleh dari lapang.

hanya dapat diamati pada stadia imago karena memiliki bentuk morfologi yang telah sempurna. Karakter umum yang menjadi penciri antar spesies adalah bentuk antena, abdomen, sifunkuli, kauda, dan seta pada tubuh. Karakter morfologi tersebut diamati dengan menggunakan mikroskop digital model Olympus CX21FS1 dan pengambilan gambar spesies menggunakan mikroskop LEICA M205 C.

\section{Perbanyakan dan pemeliharaan kutudaun}

Kutudaun $R$. rufiabdominale dan $T$. nigriabdominalis yang diperoleh dari lapang diperbanyak pada akar padi varietas Ciherang di wadah plastik berdiameter $10 \mathrm{~cm}$ dengan tinggi $8 \mathrm{~cm}$ dan ditutup dengan kain kasa. Kutudaun diletakkan pada akar padi menggunakan kuas halus nomor 1. Panjang akar padi ratun yang digunakan untuk pemeliharaan sekitar $4 \mathrm{~cm}(3 \mathrm{~cm}$ di bawah pangkal akar $+1 \mathrm{~cm}$ di atas pangkal akar). Setiap wadah pemeliharaan berisi tiga akar padi ratun dan dua imago kutudaun. Setiap spesies kutudaun ( $R$. rufiabdominale dan $T$. Nigriabdominalis) dipelihara pada wadah yang terpisah.

\section{Pengamatan biologi dan statistika demografi}

Populasi kohort merupakan sejumlah individu yang memiliki umur seragam. Nimfa instar satu R. rufiabdominale dan $T$. nigriabdominalis dalam populasi kohort diinfestasikan pada padi ratun varietas Ciherang yang berasal dari sawah di Situgede, Bogor. Panjang akar padi ratun yang digunakan adalah $4 \mathrm{~cm}(3 \mathrm{~cm}$ di bawah pangkal akar $+1 \mathrm{~cm}$ di atas pangkal akar). Nimfa instar satu kutudaun tersebut diinfestasikan masing182 masing ke dalam 60 wadah plastik berdiameter $5 \mathrm{~cm}$ dengan tinggi $4,8 \mathrm{~cm}$. Setiap wadah berisi satu nimfa kutudaun.

Peubah yang diamati, yaitu lamanya waktu tiap instar, siklus hidup, praoviposisi, lama hidup, dan keperidian kutudaun di akar padi. Siklus hidup kutudaun tersebut diamati mulai dari nimfa instar 1 diinfestasikan hingga melahirkan nimfa instar satu untuk pertama kalinya. Masa praoviposisi diamati sejak kutudaun menjadi imago hingga melahirkan nimfa instar satu untuk pertama kalinya. Lama hidup kutudaun dimulai dari hari pertama menjadi imago hingga imago tersebut mati. Keperidian kutudaun berasal dari jumlah nimfa yang dilahirkan setiap imago per hari selama hidupnya. Data hasil pengamatan disusun dalam neraca kehidupan.

Pengamatan peluang hidup $\left(1_{x}\right)$ dilakukan dengan cara menghitung jumlah individu kutudaun di akar padi yang hidup tiap harinya. Pengamatan keperidian harian $\left(m_{x}\right)$, yaitu rata-rata jumlah nimfa kutudaun yang dilahirkan oleh imago setiap harinya pada umur (x). Data peluang hidup dan keperidian harian dapat digambarkan dalam bentuk kurva dan diperoleh neraca kehidupan.

Neraca kehidupan kohort merupakan neraca kehidupan yang mengikuti perkembangan kohort dimulai dari nimfa instar satu sampai imago terakhir yang mampu bertahan hidup. Data mengenai pengamatan kohort kutudaun di akar padi disusun dalam neraca kehidupan. Birch (1948) menyatakan bahwa parameter demografi yang dihitung meliputi:

1. Laju reproduksi bersih $(\mathrm{Ro})=\sum 1_{\mathrm{x}} \mathrm{m}_{\mathrm{x}}$;

2. Laju reproduksi kotor $(\mathrm{GRR})=\sum \mathrm{m}_{\mathrm{x}}$;

3. Laju pertambahan intrinsik $(r)=\sum 1_{x} m_{x} e^{-r x}$;

4. Rataan masa generasi $(T)=\sum x l_{x} m_{x} / \sum 1_{x} m_{x}$;

5. Populasi berlipat ganda (DT) $=\ln (2) / \mathrm{r}$.

\section{HASIL}

\section{Biologi $R$. rufiabdominale dan T. nigriabdomi- nalis}

Pengamatan biologi kutudaun di akar padi dilakukan pada kedua spesies kutudaun, yaitu $R$. rufiabdominale dan T. nigriabdominalis. Setiap kutudaun mengalami fase perkembangan paurometabola, yang dimulai dari nimfa instar I sampai instar IV dan imago. Bentuk morfologi kutudaun 
setiap instar hampir sama, akan tetapi warna dan ukuran tubuhnya mengalami perubahan pada setiap instarnya.

Spesies T. nigriabdominalis mengalami perkembangan lebih lama daripada spesies $R$. rufiabdominale (Tabel 1). Siklus hidup dan lama hidup $R$. rufiabdominale dan T. nigriabdominalis berturut-turut adalah 4,98 dan 5,25 hari; 15,94 dan 18,11 hari. Keperidian imago $R$. rufiabdominale $(67,44 \pm 4,72$ individu) lebih tinggi dari keperidian imago T. nigriabdominalis (11,11 $\pm 2,71$ individu). Nilai rataan keperidian harian tertinggi pada R. rufiabdominale adalah 7 nimfa, tetapi untuk T. nigriabdominalis adalah 3,2 nimfa. Puncak keperidian $R$. rufiabdominale sebanyak 5 kali, sedangkan pada $T$. nigriabdominalis 3 kali. $R$. rufiabdominale tidak lagi menghasilkan nimfa pada umur 33 hari dan T. nigriabdominalis pada umur 22 hari.

Statistik demografi $R$. rufiabdominale dan $T$. nigriabdominalis

Hasil penelitian ini menunjukkan bahwa adanya perbedaan parameter demografi dari kedua kutudaun yang diamati (Tabel 2). Nilai rataan jumlah nimfa yang dilahirkan oleh kedua imago kutudaun berbeda antar spesies (Gambar 2). Laju reproduksi kotor (GRR) dan laju reproduksi bersih (Ro) tertinggi terdapat pada $R$. rufiabdominale. Nilai GRR dan Ro yang tinggi pada $R$. rufiabdominale memperlihatkan tingkat kesesuaian hidup terhadap tanaman inang. Nilai Ro pada $R$. rufiabdominale menunjukkan bahwa generasi berikutnya akan meningkat sebanyak 62,18 kali dari generasi sebelumnya, sedangkan nilai Ro pada T. nigriabdominalis hanya meningkat sebanyak 5,18 kali. Pola tersebut yang sama diperlihatkan pula pada nilai pertambahan intrinsik (r) antar spesies kutudaun, paling tinggi terdapat pada R. rufiabdominale. Nilai $\mathrm{r} T$. nigriabdominalis $(0,14$ nimfa per hari) lebih rendah daripada $R$. rufiabdominale (0,46 nimfa per hari), sedangkan nilai pada rataan masa generasi $(\mathrm{T})$ dan populasi berlipat ganda (DT) lebih tinggi pada spesies T. nigriabdominalis. Nilai rataan lama generasi pada $R$. rufiabdominale dan $T$. nigriabdominalis berturut-turut adalah 8,93 hari dan 11,85 hari. Waktu yang dibutukan untuk populasi berlipat ganda pada $R$. rufiabdominale adalah 1,50 hari, sedangkan pada T. nigriabdominalis 4,99 hari.

Tabel 1. Biologi Rhopalosiphum rufiabdominale dan Tetraneura nigriabdominalis di akar padi

\begin{tabular}{lcc}
\hline \multirow{2}{*}{ Parameter } & \multicolumn{2}{c}{ Rataan \pm SE (hari) } \\
\cline { 2 - 3 } & R. rufiabdominale & T. nigriabdominalis \\
\hline Instar 1 & $1,76 \pm 0,07$ & $3,00 \pm 0,17$ \\
Instar 2 & $1,03 \pm 0,58$ & $1,93 \pm 0,13$ \\
Instar 3 & $1,20 \pm 0,05$ & $1,93 \pm 0,15$ \\
Instar 4 & $0,98 \pm 0,02$ & $1,60 \pm 0,17$ \\
Siklus hidup & $4,98 \pm 0,09$ & $5,25 \pm 0,93$ \\
Praoviposisi & $0,15 \pm 0,05$ & $0,32 \pm 0,09$ \\
Lama hidup imago & $15,94 \pm 0,99$ & $18,11 \pm 1,54$ \\
Keperidian & $67,44 \pm 4,72$ individu & $11,11 \pm 2,71$ individu \\
\hline
\end{tabular}

Tabel 2. Statistik demografi spesies Rhopalosiphum rufiabdominale dan Tetraneura nigriabdominalis

\begin{tabular}{lccc}
\hline Parameter & R. rufiabdominale & T. nigriabdominalis & Satuan \\
\hline GRR & 110,56 & 22,67 & Individu/generasi \\
Ro & 62,18 & 5,18 & Individu/induk/generasi \\
r & 0,46 & 0,14 & Individu/induk/hari \\
T & 8,93 & 11,85 & Hari \\
DT & 1,50 & 4,99 & Hari \\
\hline
\end{tabular}

GRR: laju reproduksi kotor; Ro: laju reproduksi bersih; r: laju pertambahan instrinsik; T: rataan lama generasi; DT: waktu populasi berlipat ganda. 
A

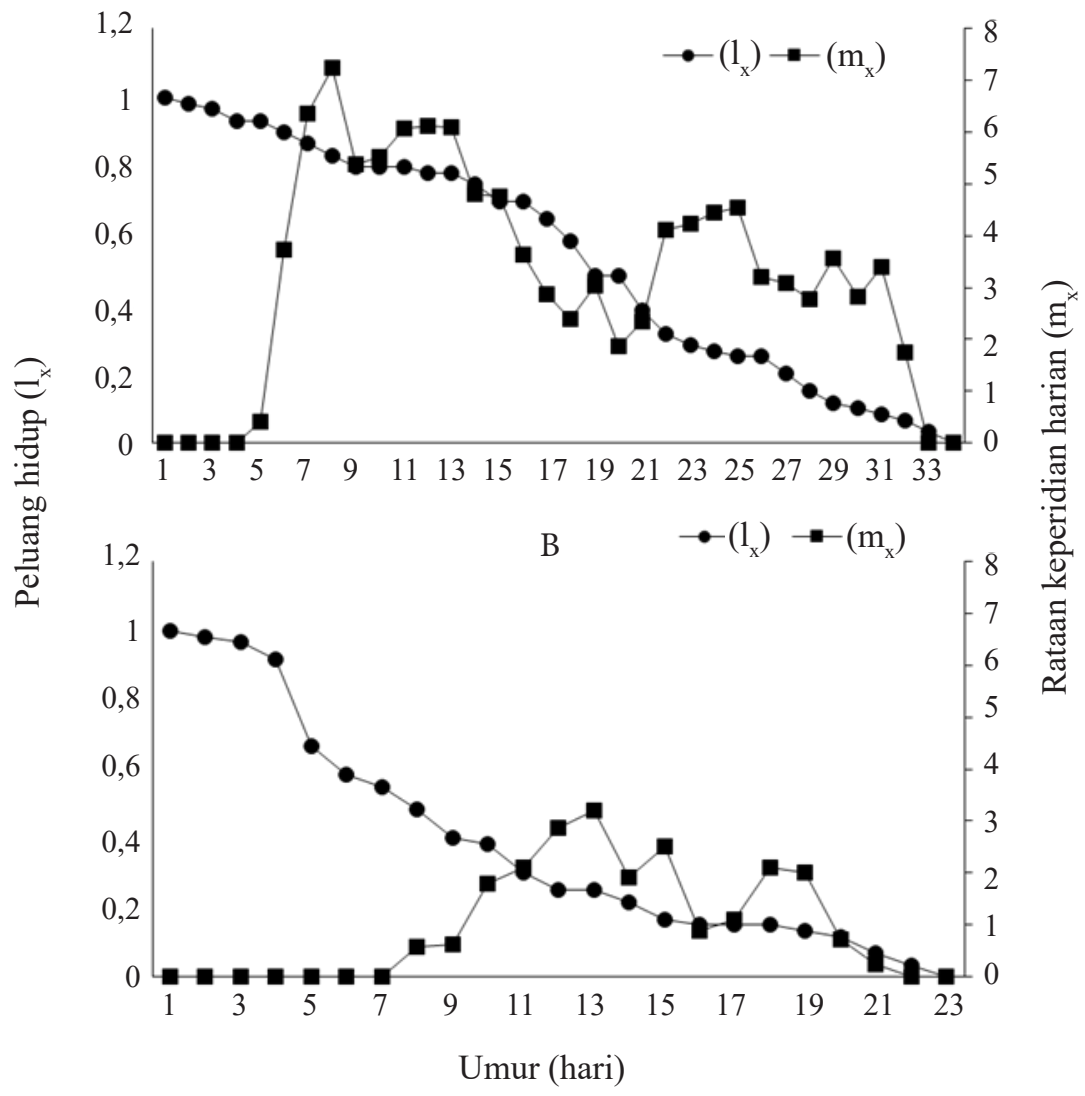

Gambar 2. Peluang hidup $\left(1_{\mathrm{x}}\right)$ dan rataan keperidian harian $\left(\mathrm{m}_{\mathrm{x}}\right)$ pada A: Rhopalosiphum rufiabdominale; dan B: Tetraneura nigriabdominalis.

\section{PEMBAHASAN}

Hasil analisis nilai rataan biologi $R$. rufiabdominale berbeda dengan $T$. nigriabdominalis. Perbedaan lama siklus hidup serangga menurut Morgan et al. (2001), dipengaruhi oleh spesies serangga, suhu, tanaman inang, serta metode perbanyakan serangga yang digunakan. Perbedaan kedua spesies kutudaun tersebut mempengaruhi lamanya siklus hidup yang dilalui oleh masing-masing spesies.

Lamanya perkembangan siklus hidup $T$. nigriabdominalis secara tidak langsung akan berpengaruh terhadap waktu reproduksinya. Semakin lama waktu yang diperlukan untuk mencapai fase imago maka semakin lama pula waktu untuk bereproduksi karena fase atau tahapan untuk berproduksi kutudaun terjadi pada fase imago. Kozlowski (1992) menyebutkan bahwa tertundanya waktu reproduksi akan berdampak terhadap peningkatan mortalitas sebelum bereproduksi, penurunan masa reproduksi, penurunan output reproduksi, dan waktu generasi menjadi lebih lama.

Waktu praoviposisi kedua kutudaun ini berbeda, $R$. rufiabdominale lebih cepat dibandingkan $T$. nigriabdominalis. Cepatnya waktu praoviposisi akan berpengaruh pada banyaknya jumlah keperidian karena penundaan masa praoviposisi akan mengakibatkan proses tertundanya imago untuk melahirkan nimfa. Salah satu faktor eksternal yang mempengaruhi adalah terpenuhinya nutrisi kutudaun. Kuo et al. (2006) menuliskan bahwa nutrisi yang diserap oleh $T$. nigriabdominalis yang rendah, termasuk nitrogen dapat menyebabkan keperidiannya menurun.

Keperidian imago $R$. rufiabdominale lebih tinggi dari keperidian imago T. nigriabdominalis. Menurut Kuswanto \& Budi (2007) menyatakan bahwa meningkatnya jumlah nimfa yang dilahirkan oleh imago kutudaun dapat meningkatkan populasinya secara cepat, terutama dipengaruhi oleh faktor makanan yang tidak terbatas. Selain faktor makanan, menurut Subagyo \& Hidayat 
(2014) meningkatnya keperidian juga dipengaruhi oleh suhu.

Secara umum faktor-faktor yang mempengaruhi biologi kutudaun ini adalah suhu, nutrisi tanaman, umur inang, struktur permukaan inang, dan komposisi kimia yang ada pada tanaman (Weathersbee \& Hardee 1994). Selain faktor eksternal, faktor internal juga memberikan pengaruh terhadap biologi kutudaun. Cara adaptasi serangga tersebut terhadap lingkungan sekitar menjadi faktor penting dalam laju siklus hidupnya (Kersting et al. 1999; Razmjou et al. 2006).

Statistik demografi diperlukan untuk menduga pertumbuhan populasi suatu organisme. Pertumbuhan populasi dapat dihitung berdasarkan peluang hidup $\left(1_{\mathrm{x}}\right)$ dan rata-rata jumlah keturunan yang dihasilkan imago betina $\left(\mathrm{m}_{\mathrm{x}}\right)$. Waktu proses tersebut memiliki peranan penting dalam perkembangan suatu populasi.

Tipe bertahan hidup $R$. rufiabdominale dan T. nigriabdominalis menunjukkan kurva tipe 1 . Hal tersebut sama diperoleh pada Rhopalosiphum padi (Linnaeus) dan Sitobion avenae Fabricius (Thirakhupt \& Araya 1992). Menurut Price (1997) kurva tipe 1 adalah kematian populasi organisme yang rendah pada umur muda dan dalam jumlah besar pada umur tua, tipe 2 adalah kematian populasi suatu individu yang konstan dan tipe 3 adalah tingginya kematian populasi suatu individu yang terjadi saat umur muda. Nilai DT yang tinggi dapat menyebabkan meningkatnya laju reproduksi kotor (GRR) dan nilai reproduksi bersih (Ro). Menurut Birch (1948), nilai populasi berlipat ganda yang tinggi pada suatu individu dapat menyebabkan penurunan sumber daya lingkungan dan mempengaruhi nilai laju pertambahan intrinsik (r).

Laju pertumbuhan intrinsik merupakan kapasitas suatu populasi untuk meningkat, yang besarnya ditentukan oleh berbagai aspek yang menyangkut sejarah kehidupan, yaitu kelahiran, kematian, dan waktu perkembangan (Kurniawan 2017). Oleh sebab itu, nilai $r$ dapat dijadikan kriteria untuk menentukan kesesuaian spesies serangga terhadap tanaman inangnya. Menurut Maharani et al. (2016) semakin tinggi nilai $\mathrm{r}$ pada suatu tumbuhan inang maka semakin tinggi potensi peningkatan populasi hama pada tumbuhan inang tersebut. Nilai $\mathrm{r} R$. rufiabdominale lebih tinggi daripada T. nigriabdominalis. Nilai $\mathrm{r}$ pada $R$. rufiabdominale 0,46 , hasil tersebut tidak berbeda jauh dengan nilai $\mathrm{r}$ pada Rhopalosiphum maidis (Fitch) (Anjali et al. 2017). Siklus hidup yang panjang pada $T$. nigriabdominalis menyebabkan laju pertambahan intrinsiknya menjadi rendah. Temperatur lingkungan sangat menentukan lamanya siklus hidup serangga. $T$. nigriabdominalis yang dipelihara pada akar padi, dengan suhu optimum $\left(30^{\circ} \mathrm{C}\right)$ menghasilkan nilai $r$ lebih tinggi $(0,241)$ dan masa generasi yang lebih singkat (Kuo et al. 2006).

Tingginya nilai $r$ ini disebabkan oleh tingginya keperidian dan rendahnya mortalitas pada pradewasa dan dewasa. Akan tetapi, menurut Birch (1948), nilai laju pertambahan intrinsik (r) yang tinggi pada suatu spesies tidak selalu diartikan sebagai tingkat keberhasilan dalam suatu habitat. Hal tersebut berdasarkan adanya proses seleksi dari spesies tersebut agar nilai r-nya menjadi relatif tinggi sehingga mampu berkompetisi dengan spesies lain. Laju pertambahan intrinsik dapat digunakan untuk memprediksi pertumbuhan populasi serangga dalam jangka waktu yang panjang. Laju pertambahan intrinsik yang rendah dapat diartikan bahwa populasi suatu organisme memiliki sedikit kemungkinan untuk terus tumbuh.

\section{KESIMPULAN}

Hasil analisis statistik demografi $R$. rufiabdominale berbeda dengan $T$. nigriabdominalis. Populasi $R$. rufiabdominale berkembang 3,5 kali lebih cepat dibandingkan dengan T. nigriabdominalis pada akar tanaman padi Cigherang. Oleh karena itu, $R$. rufiabdominale berpotensi menjadi hama penting pada tanaman padi.

\section{UCAPAN TERIMA KASIH}

Penulis mengucapkan terima kasih kepada Ibu Aisyah dan semua pihak di Laboratorium Biosistematika Serangga, Departemen Proteksi Tanaman, Fakultas Pertanian, Institut Pertanian Bogor yang telah membantu penelitian ini. 


\section{DAFTAR PUSTAKA}

Anjali MS, Sridevi G, Prabhakar M, Kalpana M, Pushpavathi B. 2017. Life table-parameters and morphometrics of the corn leaf aphid, Rhopalosiphum maidis (Fitch) (Hemiptera: Aphididae), reared on sorghum host plant. Journal of Entomology and Zoology Studies 5: 558-563.

Birch LC. 1948. The intrinsic rate of natural increase of an insect population. Journal of Animal Ecology 17:15-26. doi: https://doi. org/10.2307/1605.

Blackman RL, Eastop VF. 2006. Aphids on the World's Herbaceous Plants and Shrubs. Chicester: John Wiley \& Sons.

Kersting U, Satar S, Uygun N. 1999. Effect of temperature on development rate and fecundity of apterous Aphis gossypii Glover reared on Gossypium hirsutum L. Journal of Applied Entomology 123:23-27. doi: https://doi. org/10.1046/j.1439-0418.1999.00309.x.

Kindler D, Hesler L, Elliortt N, Shufran K, Springer T. 2004. Cereal and grass hosts of the rice root Aphids, Rhopalosiphum rufiabdominalis (Sasaki), and a description of an efficient green house rearing techniques. Journal of Agricultural and Urban Entomology 21:51-59.

Kozlowski J. 1992. Optimal allocation of resources to growth and reproduction implications for agent and size at maturity. Trends in Ecology \& Evolution 7:15-19. doi: https://doi. org/10.1016/0169-5347(92)90192-E.

Kuo M, Lu W, Chiu M, Kuo Y, Hwang S. 2006. Temperature-dependent development and population growth of Tetranura nigriabdominalis (Homoptera: Pemphigidae) on three host plant. Journal of Economic Entomology 99:1209-1213. doi: https://doi.org/10.1093/jee/99.4.1209.

Kuswanto, Budi W. 2007. Model pendugaan jumlah aphids (A. craccivora Koch) secara in situ pada tanaman kacang panjang (Vigna sesquipedalis). Jurnal Ilmu-Ilmu Pertanian Indonesia 14: 69-77.

Kurniawan HA. 2017. Siklus hidup dan statistik demografi kutukebul Bemisia tabaci (Gennadius) (Hemiptera: Aleyrodidae) biotipe B dan non-B pada tanaman cabai (Capsicum annuum L.) Jurnal Entomologi Indonesia 14:143-151. doi: http://dx.doi.org/10.5994/jei.14.3.143.
Maharani Y, Rauf A, Sartiami D, Anwar R. 2016. Biologi dan neraca hayati kutu putih pepaya Paracoccus marginatus Williams \& Granara de Willink (Hemiptera: Pseudococcidae) pada tiga jenis tumbuhan inang. Jurnal Hama dan Penyakit Tanaman Tropika 16:1-9. doi: https:// doi.org/10.23960/j.hptt.1161-9.

Morgan D, Walters KFA, Aegerter JN. 2001. Effect of temperature and cultivar on pea aphid, Acyrthosiphon pisum (Hemiptera: Aphididae) life history. Bulletin of Entomological Research 91:47-52.

Price PW. 1997. Insect Ecology. $3^{\text {rd }}$ ed. New York: Wiley.

Razmjou J, Moharramipour S, Fathipour Y, Mirhoseini SZ. 2006. Effect of cotton cultivar on performance of Aphis gossypii (Hemoptera: Aphididae) in Iran. Journal of Economic Entomology 99:1820-1825. doi: https://doi. org/10.1093/jee/99.5.1820.

Saito K, Linquist B, Keobualapha K, Phanthabon T, Shiraiwa T, Hone. 2006. Cropping intensity and rainfall effects on upland rice yields in northern Laos. Plant Soil 284:175-185. doi: https://doi. org/10.1007/s11104-006-0049-5.

Subagyo VNO, Hidayat P. 2014. Neraca kehidupan kutu kebul Bemisia tabaci (Gennadius) (Hemiptera: Aleyrodidae) pada tanaman cabai dan gulma babadotan pada suhu $25^{\circ} \mathrm{C}$ dan $29^{\circ} \mathrm{C}$. Jurnal Entomologi Indonesia 11:11-18. doi: https://doi.org/10.5994/jei.11.1.11.

Thirakhupt V, Araya JE. 1992. Survival and life table statistics of Rhopalosiphum padi (L.) and Sitobion avenae (F.) (Hom., Aphididae) in single or mixed colonies in laboratory wheat cultures. Journal of Applied Entomology 113:368-375. doi: https://doi.org/10.1111/j.1439-0418.1992. tb00677.x.

Weathersbee AA, Hardee DD. 1994. Abundance of cotton aphids (Homoptera: Aphididae) and associated biological control agents on six cotton cultivars. Journal of Economic Entomology 87:258-265. doi: https://doi.org/10.1093/ jee/87.1.258. 